\title{
CDISC SDTM Specimen Collection Method Terminology
}

National Cancer Institute

\section{Source}

National Cancer Institute. CDISC SDTM Specimen Collection Method Terminology. NCI

Thesaurus. Code C132314.

Terminology associated with the specimen collection method codelist of the Clinical Data Interchange Standards Consortium (CDISC) Study Data T abulation Model (SDT M). 